\title{
Chronic diseases in the Western world: Increasing incidence or increasing overdiagnosis?
}

This issue of the SAMJ carries an important paper for South Africa (SA), outlining the trends in non-communicable disease (NCD) mortality in this country over the 13 years $1997-2010 .^{[1]}$ In this largely resource-poor country, nearly $40 \%$ of deaths during this period were due to NCDs, and of these nearly $15 \%$ were regarded as premature deaths - i.e. before the age of 45 . Another $21 \%$ were deaths between the ages of 45 and 59. This is a worrying trend in a country where we still have significant child mortality.

However, commentators in the developed world are concerned, for different reasons, about an explosion of chronic disease. In a recent article in the $B M J$, McGrail et al. ${ }^{[2]}$ question whether this increase in chronic disease truly reflects worse health. They cite a recent paper from the Global Burden of Disease Study suggesting that only $4 \%$ of the world's population is free of disease ${ }^{[3]}-$ in other words, health is an anomaly. Chronic diseases are the conditions that contribute to this alarming 'lack of health', and multimorbidity - described as the 'most common chronic condition' ${ }^{\text {'[4] }}$ - affects at least half of the population aged over $65 .{ }^{[5]}$

Given that patients with chronic conditions now account for most consultations in primary care in the developed world, ${ }^{[6]}$ and that the number of people with chronic conditions is rising faster than previously predicted, ${ }^{[7]}$ we need to start to ask some hard questions about the reason why. This is exactly what McGrail et al. ${ }^{[2]}$ are doing, remarking that this burden of disease is likely to bring the most challenges to healthcare systems in the developed world. They looked at figures on 11 chronic diseases from British Columbia, Canada, which were targeted for policy and practice change either because of their prevalence or their effect on healthcare expenditure, in 4-year windows. They found the expected increase in prevalence with age, but what struck them was the rate of increase in age-specific rates over time. For example, in 10 years the chronic disease burden in people aged $\geq 80$ years rose from an average of 1.4 conditions to 2 conditions, and in the $70-79$-year age group it rose from 1.2 to 1.5. The data showed that the increase in the age group $\geq 80$ years results from both a smaller proportion of people having no diagnosed condition (only a fifth in 2012 - 2013) and a much higher proportion having three or more conditions (almost two-fifths in 2012 - 2013). McGrail et al ${ }^{[2]}$ suggest three possible explanations for the rapid increases in rates of chronic disease - a true pandemic, particularly bad in the elderly; earlier or more vigilant recording of existing and known diagnoses; or 'diagnostic creep' - people now diagnosed with chronic disease who would not have been a decade or so ago.

We know that health declines with age, and populations in the developed world are ageing. With advances in healthcare, people are, for example, living through a heart attack that might previously have killed them - and are then left with a chronic disease label. This will account for at least some of the trend, although it is highly unlikely that this alone can explain the increase over such a short time. Population risk factors also change with time - the increased prevalence of diabetes is one such risk. There is also reason to believe that more vigilant recording of conditions accounts for at least some of this reported rise in chronic disease, particularly since doctors in many of these countries are rewarded for the number of chronic diseases they diagnose and treat over a specific time. What was apparent from the Canadian data was that there was an apparent increase in diagnosis, with no change in underlying morbidity.

However, what is really striking is that, parallel to this increase in the prevalence of chronic diseases, self-reported health status is improving - in other words, the people who are being diagnosed with multiple chronic diseases still feel pretty good. At the same time, governments - the UK is a good example - are trying to screen populations and catch disease at earlier stages. This should lead to faster increases in rates of chronic disease in younger age groups, but if anything, data show more rapid increases in diagnosis at older ages.

The most likely candidate, according to this analysis, is redefining what constitutes illness, and there is plenty of evidence for this. Bone density testing has created a vast pool of new patients with osteoporosis. Lowering of clinical thresholds for hypertension and diabetes has among other things led to substantial increases in the number of people diagnosed. ${ }^{[8,9]}$ In other words, there is overdiagnosis and hypermedicalisation. ${ }^{[9]}$

The conclusion is that, although a single explanation is unlikely, changes in data capture and diagnostic practices are more important than actual changes in health status. While this is unlikely to be the case in SA yet - except possibly among the 'worried well' in the private health sector - these are important lessons to take forward as we enter the era of National Health Insurance. Be wary of screening for chronic disease, and be particularly wary of rewarding practitioners on the basis of cases of particular illnesses diagnosed. If your patient says she is feeling well, there is a good chance that she actually is healthy!

\section{Bridget Farham \\ Acting Editor \\ ugqirha@iafrica.com}

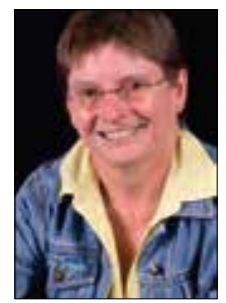

1. Nojilana B, Bradshaw D, Pillay-van Wyk V, et al., on behalf of the South African National Burden of Disease team. Emerging trends in non-communicable disease mortality in South Africa, 1997 - 2010. S Afr Med J 2016;106(5):477-484. DOI:10.7196/SAMJ.2016.v106i5.10674

McGrail K, Lavergne R, Lewis S, et al. The chronic disease explosion: Artificial bang or empirical whimper? BMJ 2016;352:11312. DOI:10.1136/bmj.i1312

Global Burden of Disease Study 2013 Collaborators. Global, regional, and national incidence, prevalence, and years lived with disebilty for 301 acute and chronic diseases and injuries in 188 prevalence, and years lived wh disablity for 301 acule and chronic diseases and injuries in 188 2015;386(9995):743-800. DOI:10.1016/S0140-6736(15)60692-4

4. May C. Chronic illness and intractability: Professional-patient interactions in primary care. Chronic Illn 2005;1(1):15-20. DOI:10.1177/17423953050010011201

5. Fortin M, Stewart M, Poitras ME, Almirall J, Maddocks H. A systematic review of prevalence studies on multimorbidity: Toward a more uniform methodology. Ann Fam Med 2012;10(2):142-151. DOI:http://dx.doi.org/10.1370/afm.1337

6. Jayaraman G. Defining multimorbidity for public health surveillance and epidemiology. Presented at the Canadian Society for Epidemiology and Biostatistics Annual Conference, St John's, Newfoundland, 25-27 June 2013:1-21.

Anderson G. Chronic care: Making the case for ongoing care. 2010. www.rwjf.org/content/dam/farm/ reports/reports/2010/rwif54583 (accessed 8 April 2016).

8. Kaplan RM, Ong M. Rationale and public health implications of changing $\mathrm{CHD}$ risk factor definitions. Annu Rev Public Health 2007;28:321-344. DOI:10.1146/annurev.publhealth.28.021406.144141

9. Welch HG, Schwartz LM, Woloshin S. Overdiagnosed. Boston, MA: Beacon Press, 2011. 